\title{
AN ASSESSMENT OF THE NEFF CIRCULATOR
}

\author{
Peter L. Jones, f.F.A.R.C.S. AND John Prosser, f.f.A.r.C.S.
}

\section{INTRODUCTION}

THE PROBLEMS of eliminating expired carbon dioxide from anaesthetic circuits have excited the ingenuity of designers for many years. Carbon dioxide absorption systems, initially introduced in the form of "to-and-fro" circuits, produce an apparatus dead-space which tends to increase as the absorption material becomes exhausted. Means of circulating the gases through the absorber in order to reduce this deadspace were developed and these generally employed the fresh gas flow to drive some form of Venturi injection system for motive power. The first commercial model of the Aga Spiropulsator (1940) featured such a system. Of more recent origin, a Waters-type canister for paediatric anaesthesia designed by Takaoka incorporates an injector driven by fresh gas and which re-circulates anaesthetic gases around the absorber. Generally, however, the problem has been overcome by using a circle absorption system. This involves the operation of 1 -way valves by the patient which contribute to the work of breathing. Clinical spirometers designed for the measurement of basal metabolic rate frequently employ an electrically driven fan which circulates the enclosed atmosphere in the belief that this eliminates the work of breathing through the apparatus.

None of these systems resolved the problem of under-mask dead-space. Most attempts to achieve this have involved a closer fitting face-mask (e.g. the RendellBaker Soucek Mask) or partitioned T-pieces (e.g. the Rendell-Baker Partitioned T-piece and the Bird Partitioned Y-connector). Revell (1959) ${ }^{1}$ proposed a device which incorporated a small compressed-air-driven turbine for impelling anaesthetic gases around the absorption circle, which, in association with a partitioned Y-piece, was found to be effective in reducing under-mask dead-space. ${ }^{2}$ Neff and his colleagues in $1968^{3}$ described a device using the fresh gas flow to drive a Venturi circulator. The authors state that the device can largely eliminate apparatus deadspace, ensure rapid mixing of the anaesthetic atmosphere, and compensate for apparatus breathing resistance. The present communication describes a detailed laboratory investigation of this device supplemented by a limited clinical evaluation.

\section{Description of Device}

The Neff Circulator is a compact device which is inserted in the inspiratory limb of a circle absorber system where it induces a circulation of gases around the system. It achieves this by means of a double-barrel Venturi injector system (see Figures 1a and $1 b$ ) in which fresh gas flow from the anaesthetic machine directed

From the Department of Anaesthetics, Welsh National School of Medicine, University Hospital of Wales, Heath Park, Cardiff, CF4 4XN. 


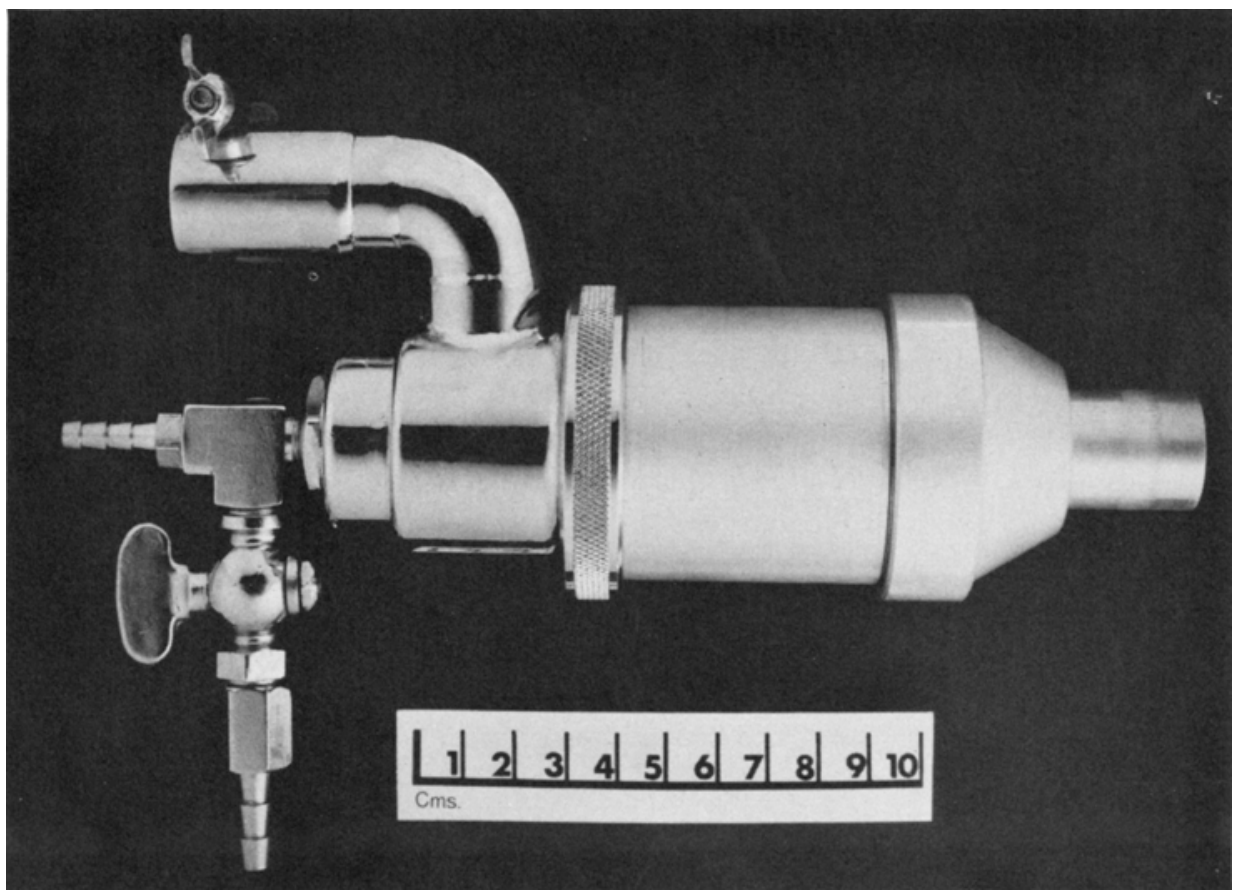

Figure la. Diagram of Neff Circulator. Only one of the two injectors is illustrated.

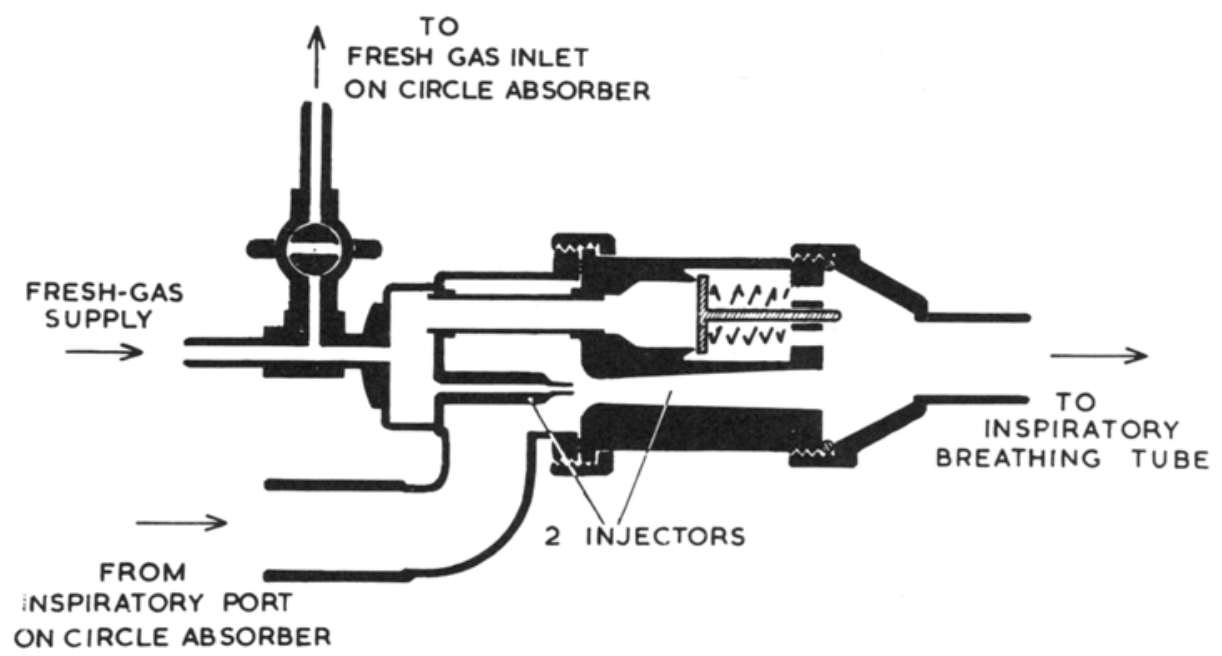

Figure 1b. Diagram of Neff Circulator. Only one of the two injectors is illustrated.

through a pair of jets entrains the circuit gases. When the back pressure from the fresh gas flow exceeds a prescribed limit, a spring-loaded relief valve opens and allows the fresh gas to spill and by-pass the Venturi system. A tap in the fresh gas line allows manual re-direction of this flow so that it may enter the circle absorber by the conventional path when it is desired to turn off the circulator. The whole 
device is constructed to a high standard of precision of anodized aluminium and chromium plated brass.

In the present study, the device has been assessed in the following categories:

1. The Venturi characteristics.

2. Performance of the circulator in a circle system.

3. Performance of the system with an artificial patient.

4. Effect of the device on conscious volunteers.

5. Effect of the device on anaesthetized patients.

\section{The Venturi Characteristics}

The jets in the Venturi impose a resistance to the flow of fresh gas resulting in a pressure transmitted back to the anaesthetic machine. The pressure may exaggerate leaks within the anaesthetic circuit. For this reason it is advisable to check periodically the flowmeter settings on the anaesthetic machine with back pressure generated by the device and to compare these with readings on a flowmeter situated at the patient end of the circuit while the spill valve is closed in order to be sure that no gas leaks are occurring. In early models of the circulator, the pressure relief valve did not operate until relatively high pressures were developed. Such back pressures could cause large errors in the output of calibrated vaporizers used in the anaesthetic circuit. ${ }^{4}$ Modifications to this valve and to the jets now result in the back pressure being limited to approximately 60 millimeters of mercury. The circulator jet characteristics are illustrated in Figure 2. It may be seen from the graph that if the by-pass pressure characteristics are maintained, the maximum flow passing through the Venturi itself is limited to approximately 3 litres/min and all fresh gas in excess of that will by-pass the device. The limited back pressure which is transmitted to the rotameters of the anaesthetic machine is not sufficient to cause any significant error in their readings.

\section{1b. The Entrainment Characteristics of the Injector}

The entrainment characteristics of the injector were measured for a range of back-pressures. For clarity, the pressure relief valve was blocked so that all fresh gas was delivered to the jets as driving gas. The jet gas flow was measured using a rotameter while the output flow was recorded with a pneumotachograph head. The outflow path was progressively obstructed and the back-pressure so generated was monitored using a strain gauge manometer. Figure 3 summarizes the results obtained. For zero back-pressure, a linear characteristic is produced having an entrainment ratio of approximately 14:1. The performance is very sensitive to back pressure, particularly at low driving gas flows.

\section{The Performance of the Circulator in a Circle System}

The performance of the circulator within a circle system is very dependent upon the characteristics of the absorption circuit. Figure 4 indicates the flow/pressure characteristics of the circuit in which the injector has been tested. The circle absorber used throughout this investigation is the B.O.C. Mark III Absorber which features a low resistance, circle absorber with mica-disc unidirectional valves. The breathing tubes were fitted with British Standard corrugated antistatic rubber 


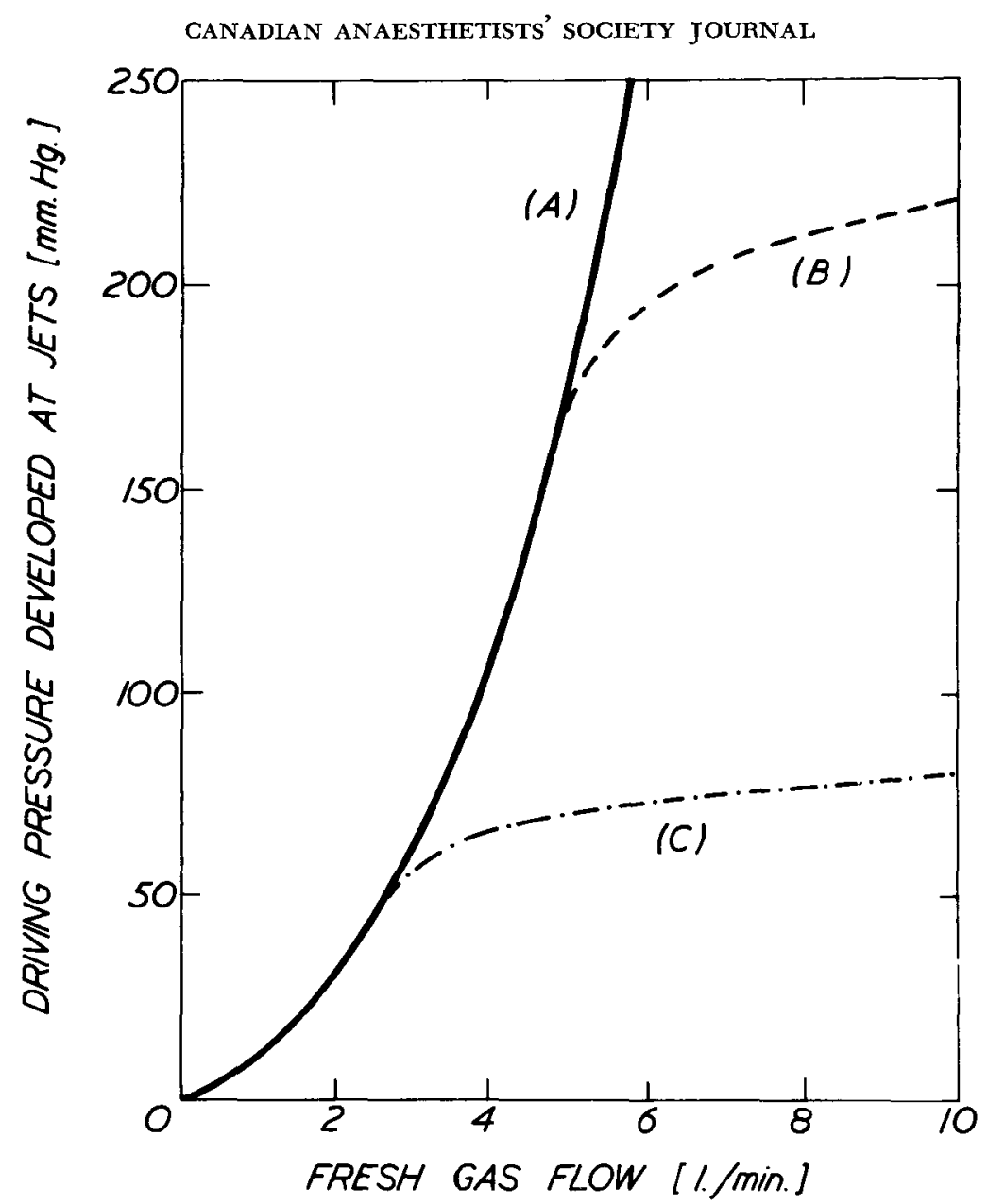

Figure 2. Driving pressure/Flow characteristics of jets. (a) Pressure relief valve inoperative. (b) Early model pressure relief valve. (c) Typical performance with current design pressure relief valve.

hose, a conventional T-piece and mask. During spontaneous respiration the resistance on inspiration is different from that on expiration. On inspiration the gas is taken directly from the bag through the breathing tube, whilst on expiration the resistance of the absorber has to be overcome. The circulator, on the other hand, must overcome the resistance of the absorber, both one-way valves, both tubes and the T-piece. The resistance so encountered is rather less than the sum of the inspiratory and expiratory resistances.

The effect of the resistances upon the performance of the circulator in the B.O.C. Mark III Absorber is indicated in Figure 5. Only one curve has been included since there was little difference between the conventional T-piece and the "Double Entry" mask. The curve shows clearly the dependence of the circulation flow upon the fresh gas flow. A 5-litre fresh gas flow rate which produces a circulating flow of 36 litres/minute when the relief valve remains closed would normally only deliver 


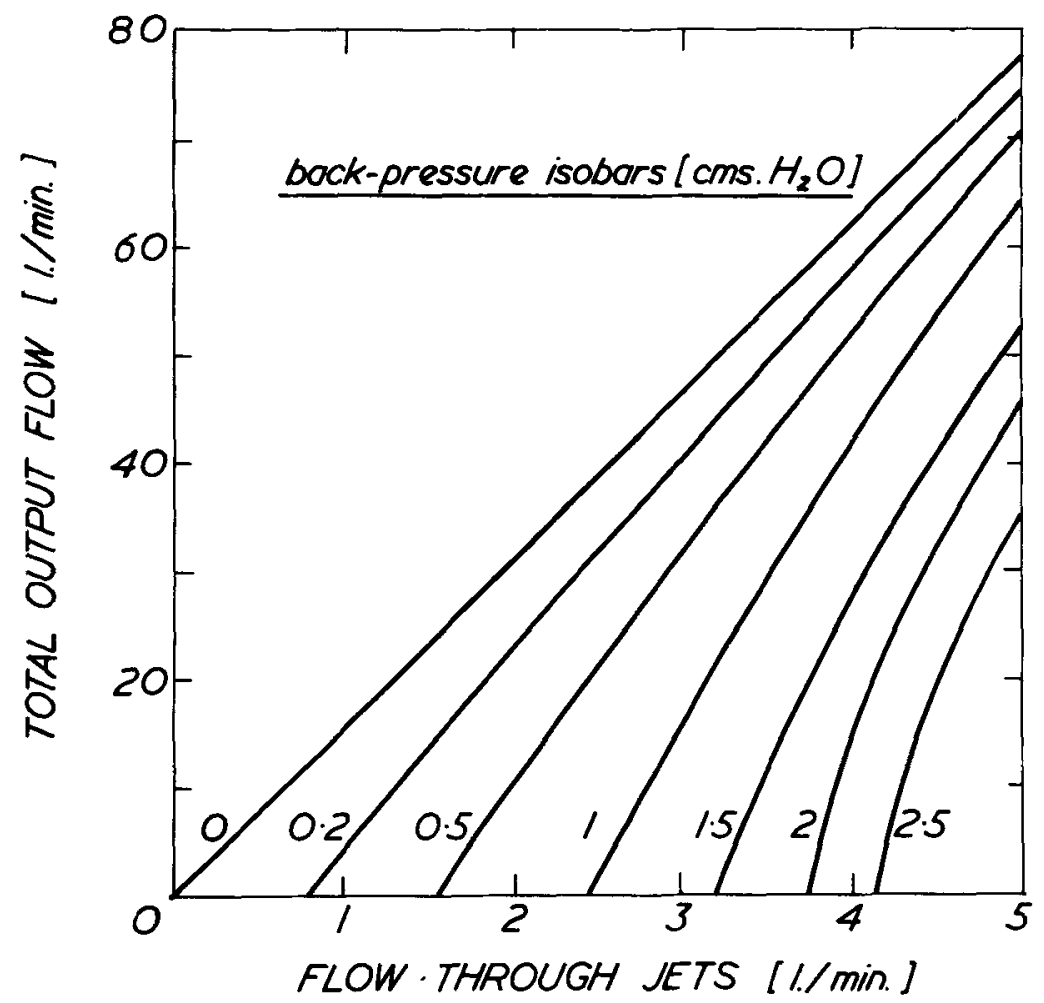

Figure 3. Entrainment characteristics of circulator. Pressure relief valve inoperative.

about $3 \frac{1}{2} \mathrm{l} / \mathrm{min}$ to the jets and thus entrain a circulating flow of approximately 20 $1 / \min$.

The Performance of the System with an Artificial Patient.

(a) Apparatus Dead-Space

A mechanical analogue of a patient was constructed in order to establish the effect of the circulator upon apparatus dead-space and upon the work of breathing through the circle system. The "patient" was set to "breathe" tidal volumes of 500 $\mathrm{ml}$ at a frequency of 20 breaths per minute (i.e. minute volume equals 10 litres). The physiological dead-snace was adjusted to approximately $200 \mathrm{ml}$ and the carbon dioxide production to $180 \mathrm{ml}$ per min. The circuit is shown in Figure 6. In order to ensure normal under-mask dead-space, the artificial patient was equipped with a moulded human face facsimile. The mixing chamber was necessary to ensure consistent sampling. The total dead-space was calculated from the Bohr equation. The values of the mixed expired $\mathrm{P}_{\mathrm{CO}_{2}}$ for the calculation was obtained by replacing the dummy face with a "Ruben" inflating valve and collecting the expired gas in a bag before sampling. The same Katharometer was used for all carbon dioxide analyses. The "patient" dead-space so calculated was $198.5 \mathrm{ml}$. The apparatus was then strapped to the re-connected face and the "patient" dead-space re-assessed. The apparatus dead-space was the difference between the total and the patient 


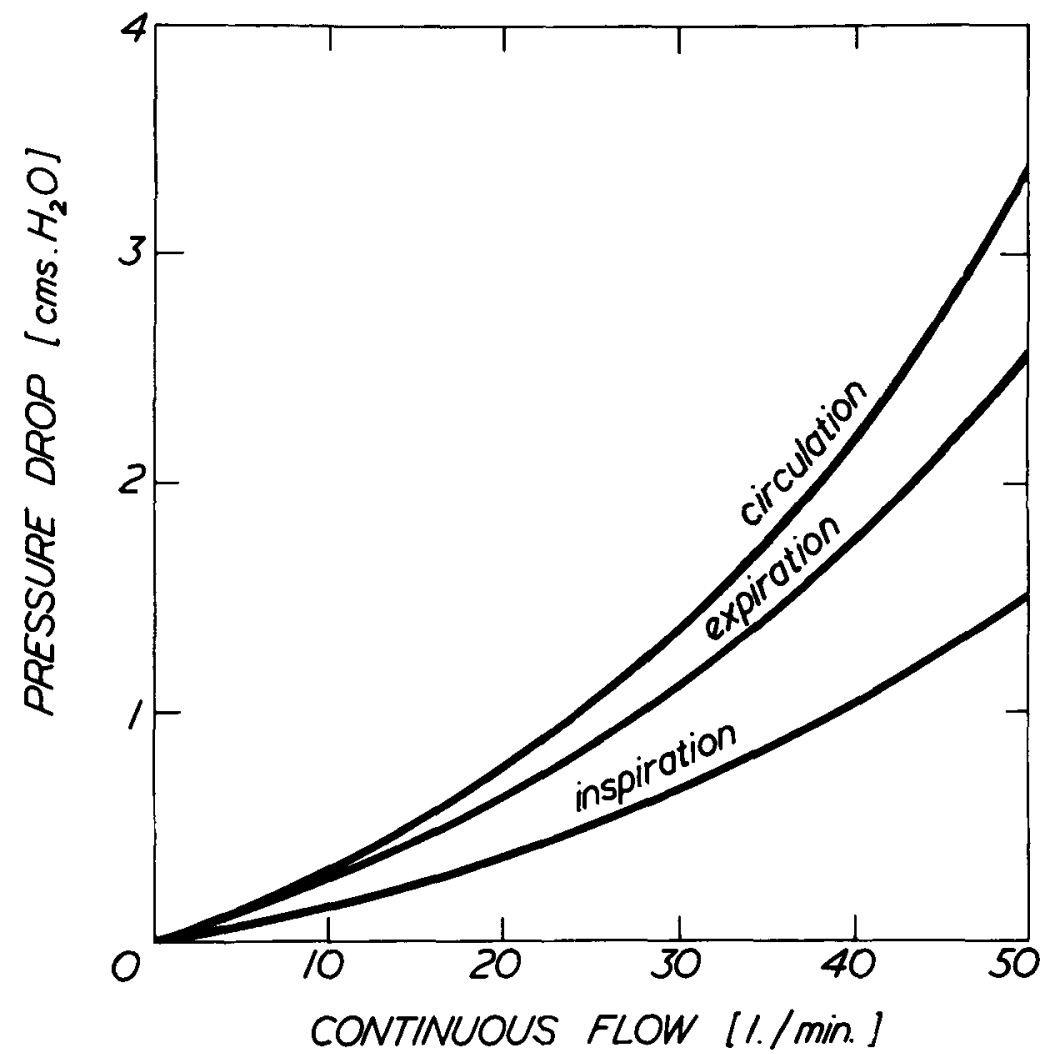

Figure 4. Pressure/Flow characteristics of B.O.C. Mk III circle absorber. Circulator not in circuit.

dead-spaces. Figure 7 shows the effect of increasing fresh gas flow upon the apparatus dead-space for the various circuits. The conventional T-piece produced little change in apparatus dead-space when used in association with the circulator. However, the M.I.E. "Double Entry" mask, in which gas enters at one side and leaves at the opposite side, allowed not only the elimination of apparatus deadspace but also caused some erosion of the "patient" dead-space. The "Dupaco Divided Y," a partitioned Y-connector for use with conventional face masks, produced an intermediate reduction. In these experiments, the system was capable of eliminating apparatus dead-space only in conjunction with the "Double-Entry" mask and there was limited value in using either form of T-piece with a conventional mask.

\section{The Effect of the Injector upon the Work of Breathing through Circle}

\section{Absorption System}

The work of breathing through an apparatus such as a circle absorber is executed entirely in overcoming the resistance of the apparatus. In this situation the work per breath may be calculated by plotting volume displacement against the pressure developed between the mask and the bag of the apparatus and computing the area 


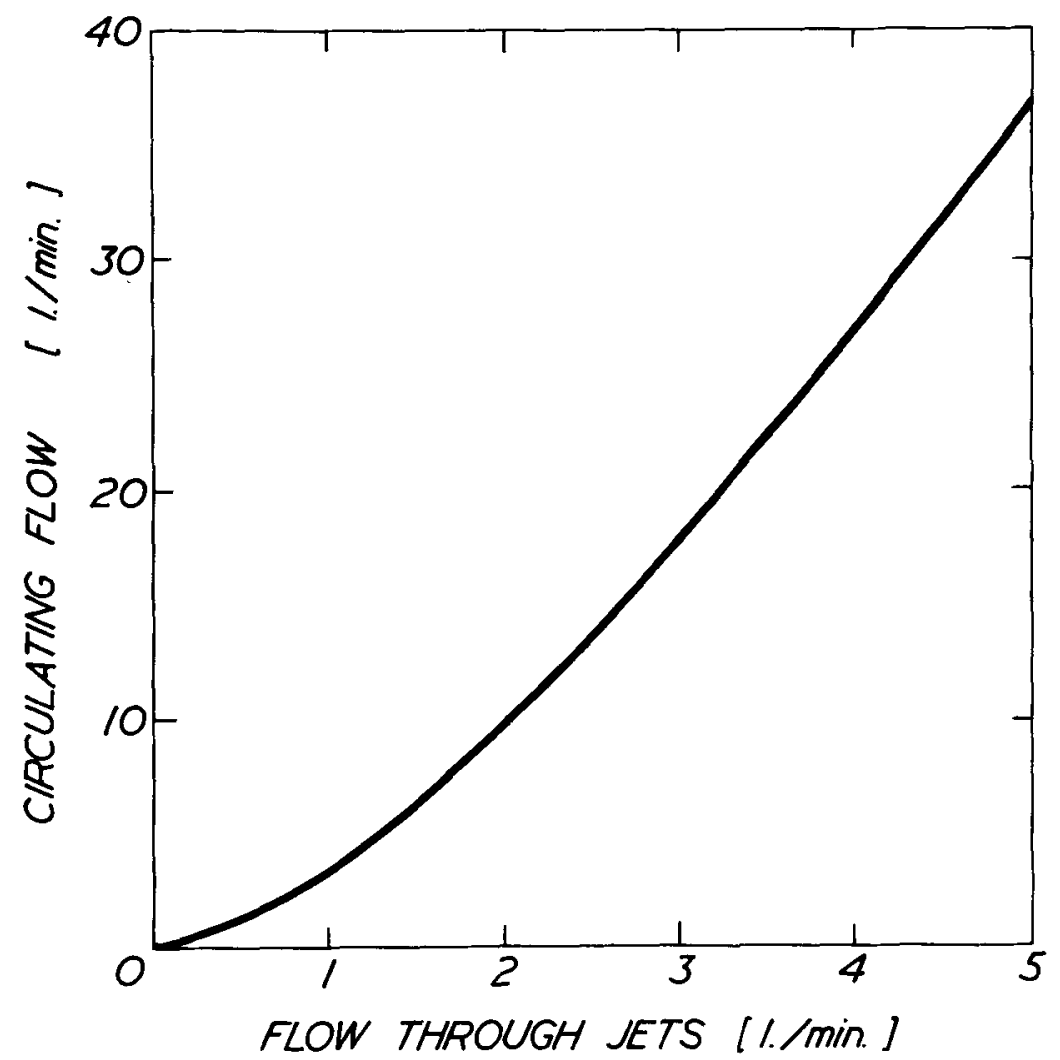

Frgure 5. Circulating flow induced by circulator. Pressure relief valve inoperative.

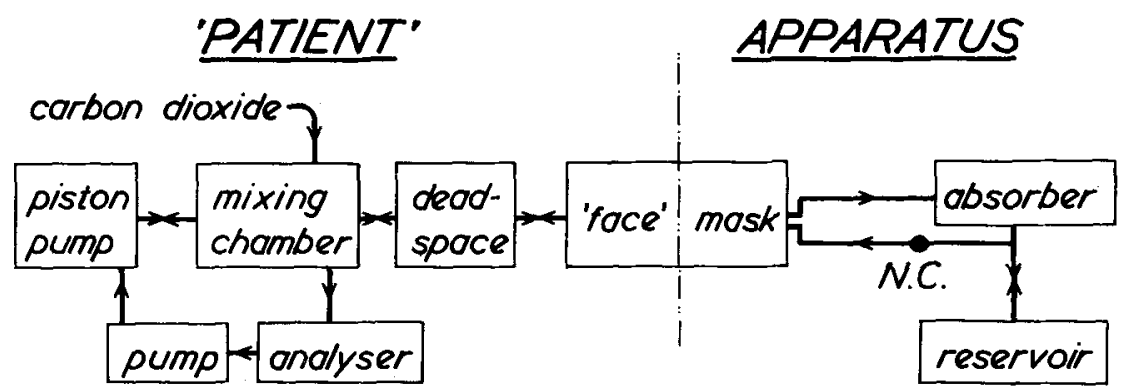

Figure 6. Schematic diagram of patient analogue used for dead-space measurement. "N.C." indicates position of Neff Circulator.

of the loop so obtained. In the bench experiment, the flow pattern was generated by a B.O.C. "Beaver" ventilator connected to the artificial face to which, in turn, the mask of the apparatus was strapped. The bag was replaced by a hose communicating with a water spirometer of lightweight construction in which a lowtorque potentiometer acted as a displacement-transducer. A differential pressure transducer was connected across the apparatus and both transducer outputs were 


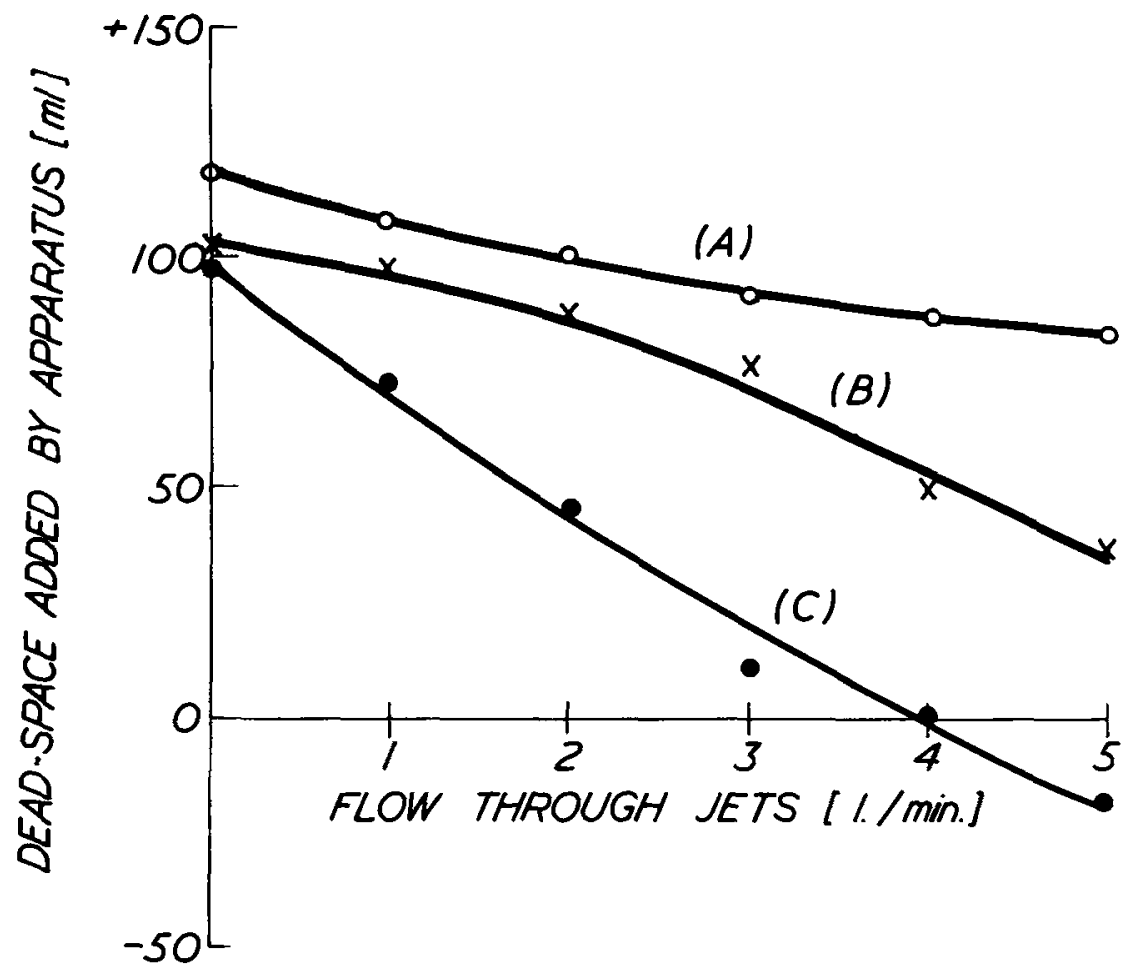

Figure 7. The effect of the circulator upon apparatus dead-space with various Mask arrangements. (a) Conventional face mask + Y-connector. ( $b$ ) Conventional face mask + "Dupaco Divided Y-connector." (c) M. \& I.E. Double Entry Mask.

used to drive a fast response X-Y plotter. The shape of the loop produced with each breath is illustrated in Figure 8. The loop is distorted because of the peculiar flow pattern of the Beaver ventilator and so the area of the loop does not necessarily simulate quantitatively the work that would be done by a patient breathing at the same tidal volume and frequency. However, it is more constant than would be achieved by a patient and therefore indicates more distinctly the changes in work that occur with variation of fresh gas flow rates in a circulator. In Figure 9 the work per breath has been plotted against the fresh gas flow using the M.I.E. "DoubleEntry" mask. The dotted line indicates the work of breathing when the injector was completely out of circuit and the fresh gas was introduced in the conventional manner. There is no evidence from this experiment that so long as ventilation is maintained unchanged, the injector reduces the work of breathing through the apparatus.

The explanation for this behaviour is two-fold. If one assumes a circulation flow sufficient to keep the one-way valves fully open all the time, then the patient will not have to operate the valves and this will slightly reduce the work of breathing. A more important effect will be that under these conditions the patient will now be inhaling by accelerating gas in the inspiratory limb of the tubing and also by decelerating the flow in the expiratory limb. This means that he will be breathing 


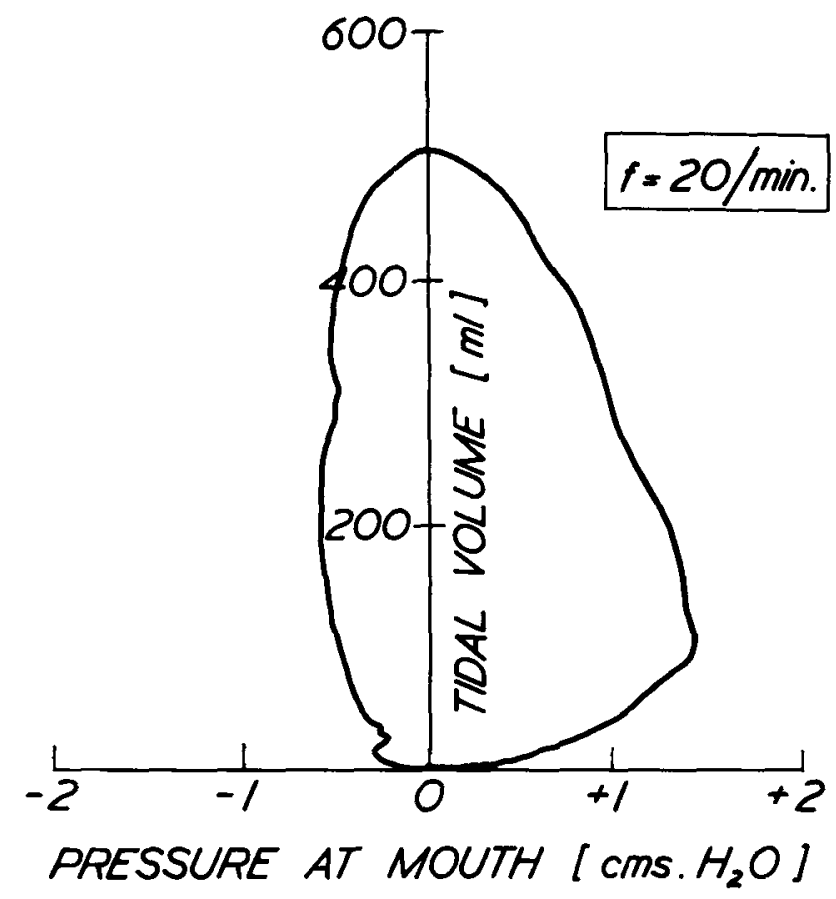

Figune 8. Pressure/Volume loop produced using the Analogue Lung.

through two tube resistances in parallel instead of only one. This would tend to reduce the work of breathing. Such a generalization, however, takes no account of turbulence induced by the circulator flow and which causes an increase in work. The combined operation of these two factors accounts for the dipped, curved response.

The significance of these findings depends very much upon the patient. The importance of the increased apparatus work depends upon the total patient work of breathing. For example, if the apparatus work constituted only 2 per cent of the total work of breathing, even doubling it ( to 4 per cent) would be hardly likely to be of major importance. In addition, the bench experiment does not take into account the effect upon the patient of eliminating apparatus dead-space. It might be expected that the total ventilation necessary to maintain a $\mathrm{PaCO}_{2}$ constant would be reduced when using the circulator and this might provide a reduction in the total work of breathing which would be large enough to negate an increase in work due to the apparatus resistance.

\section{The Effect of the Device upon Conscious Volunteers}

In these experiments the volunteers received no premedication. They were thus able to modify their ventilation to compensate for changes in apparatus dead-space. The experimental design allowed the work of breathing through the apparatus and the work of breathing due to compliance and airway resistance of the lung to be measured. The apparatus array is illustrated schematically in Figure 10. The volunteers, who had obligingly swallowed a $10 \mathrm{~cm}$ gas-filled oesophageal balloon, 


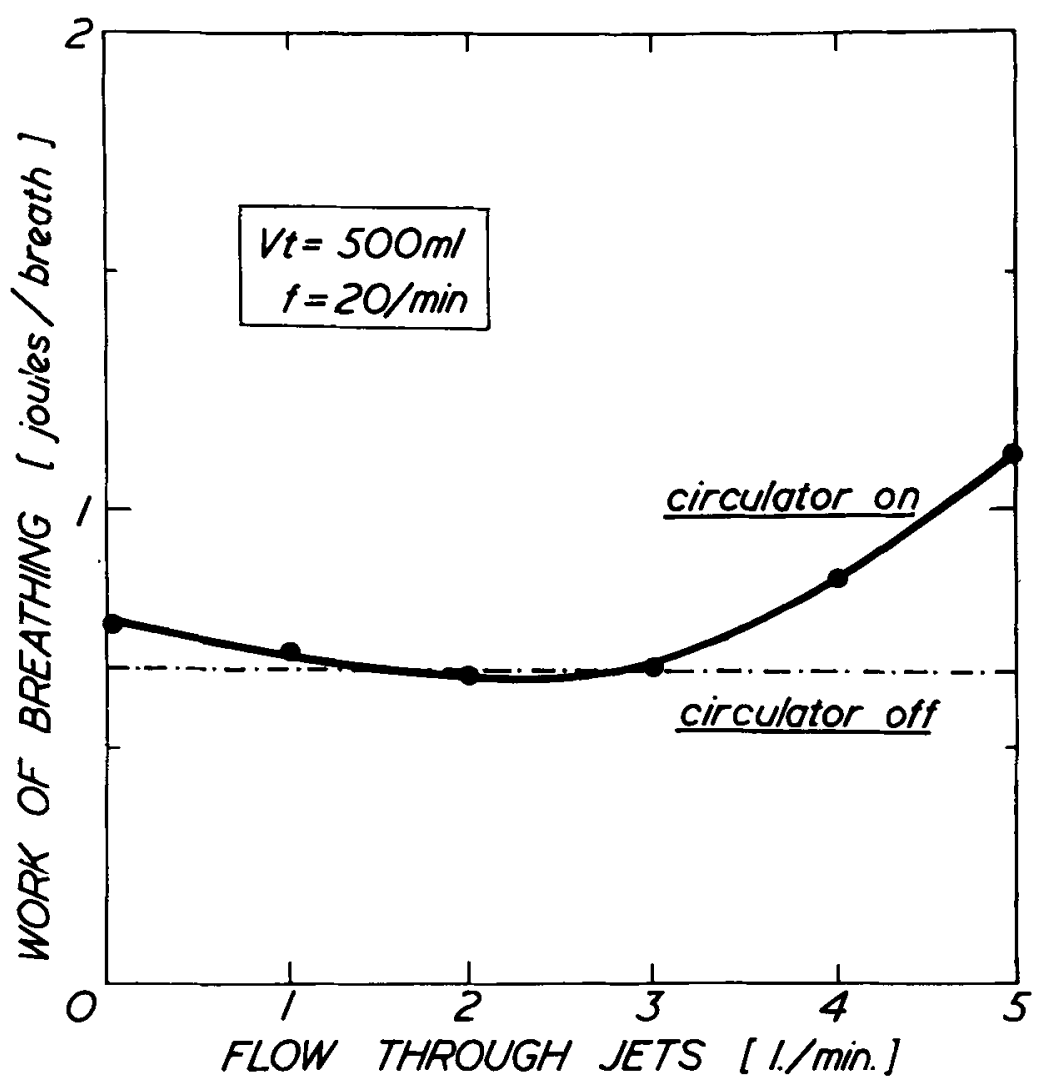

Figure 9. The effect of the circulator on apparatus work. "Circulator off" indicates circulator removed from the system.

maintained a seated posture throughout the experiments. In view of the complexity of the experiment, a limited number of representative circuit configurations were used, i.e.:

1. The circulator "on" with 5-litre fresh gas flow.

2. The circulator "OFF," indicating that the fresh gas flow is diverted through the conventional absorber inlet whilst the device remains in the circuit, i.e. there is no circulation flow.

The only mask used in this part of the investigation was the M.I.E. "Double Entry" mask since it was only with this mask that the full advantage of dead-space reduction had been shown to be available. Fifteen minutes of normal ventilation were recorded with each configuration, at the end of which the volunteer was asked to vary his depth of breathing whilst maintaining his frequency as far as possible. This enabled calibration curves of tidal volume work to be constructed. The circulator induced a mean under-mask positive pressure of the order of $1.2 \mathrm{cms}$ $\mathrm{H}_{2} \mathrm{O}$ when operational. Figure 11 illustrates the type of volume pressure loops that were obtained with this data. The vertical loop is generated by pressure gradient across the apparatus and its area indicates apparatus work. The oblique loop is 


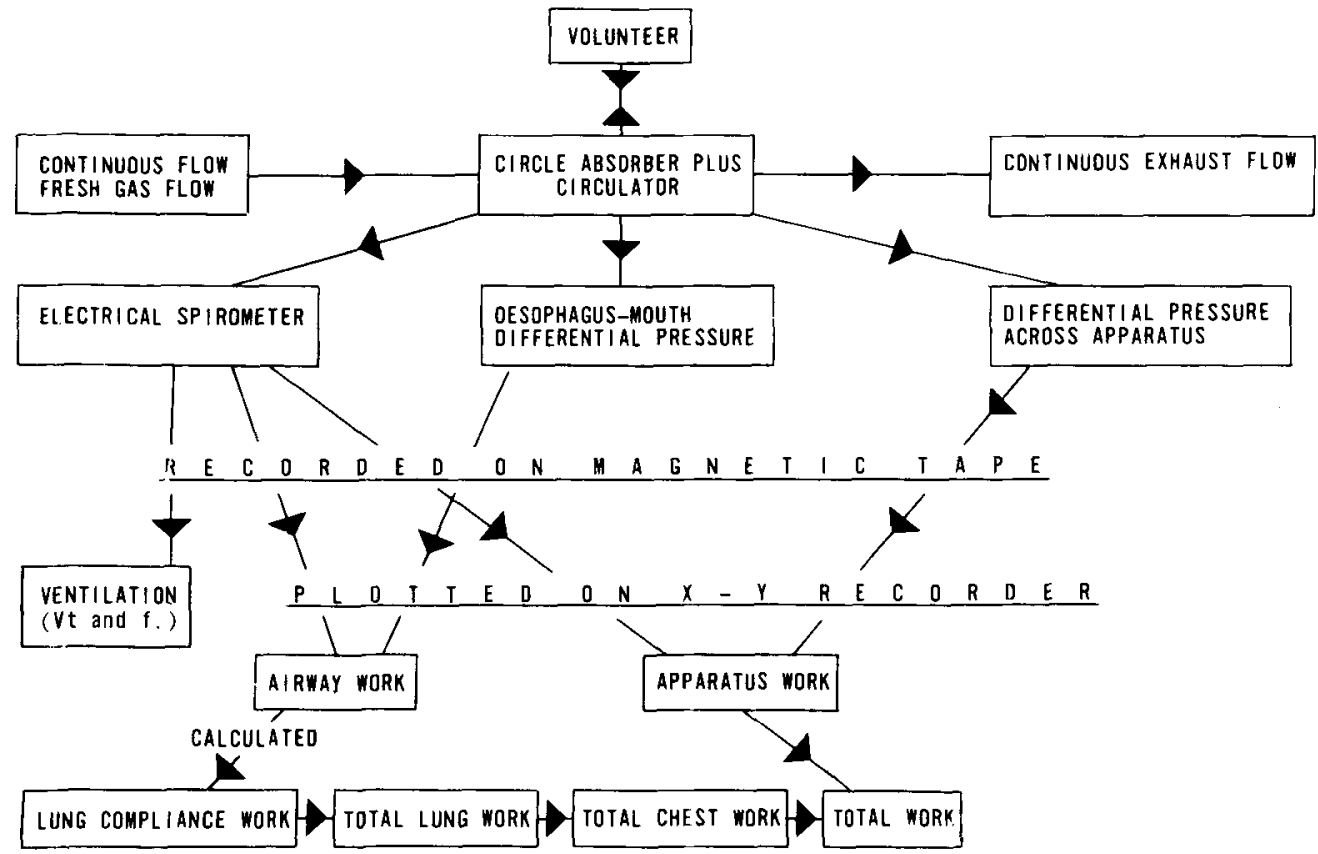

FIGURE 10. Schematic diagram of apparatus array for volunteer experiments.

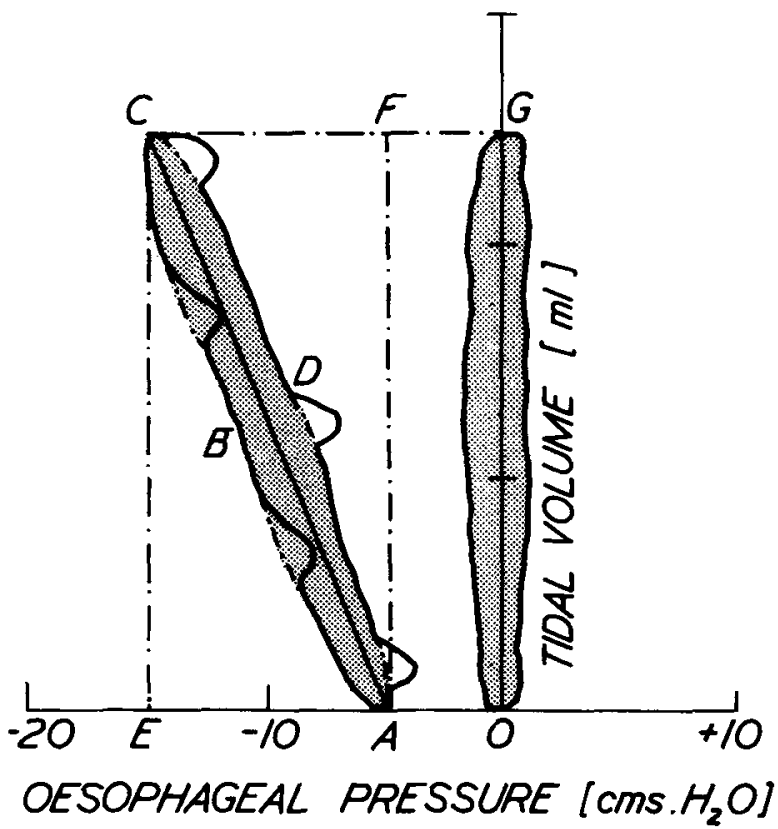

Figure 11. Pressure: volume loops obtained from volunteer experiments. The right-hand loop is derived from apparatus pressure gradient and the left-hand loop represents pressure drop between oesophagus and mouth. 


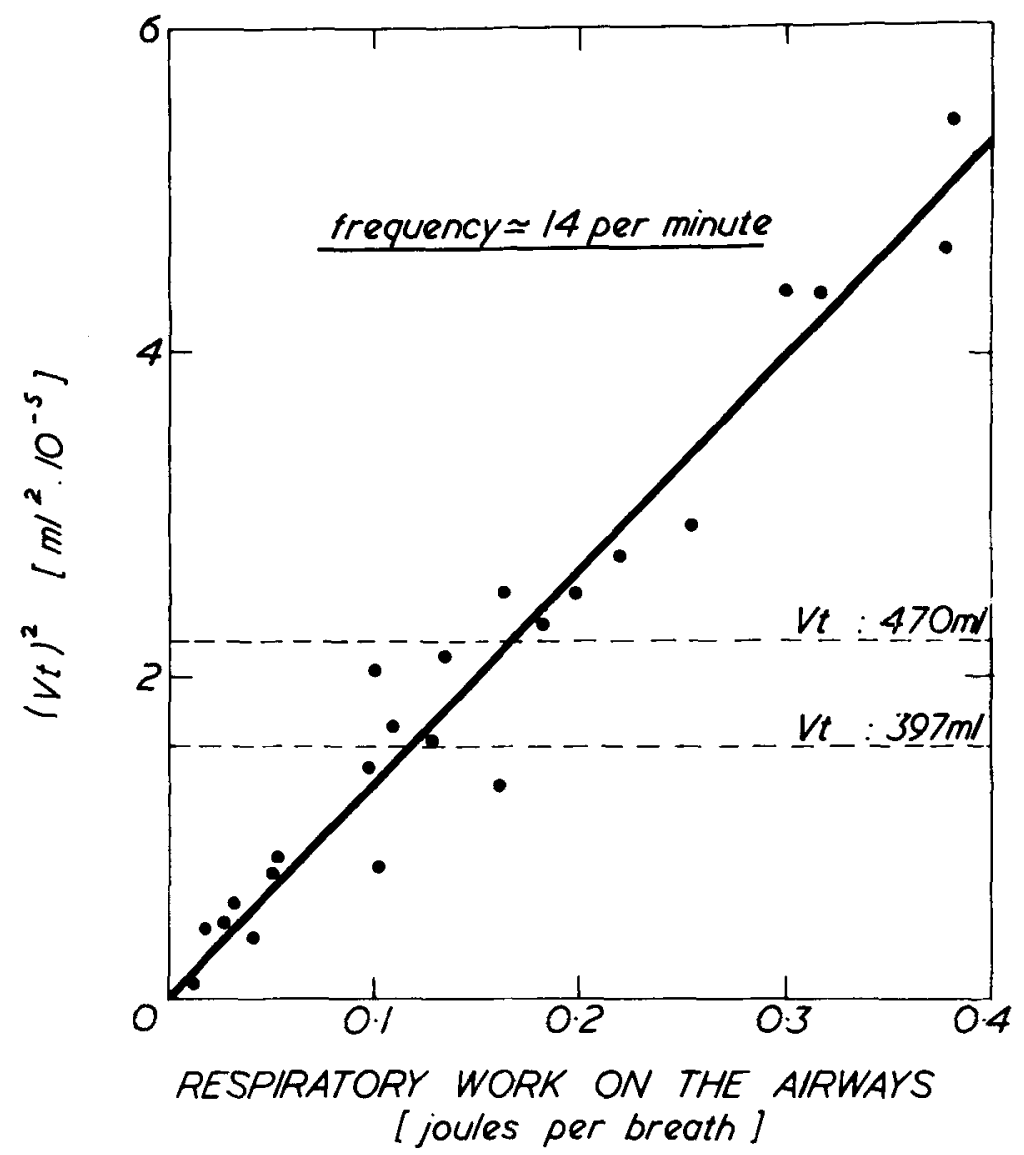

Figure 12. Relationship between airways work and tidal volume. A few points only are shown for clarity.

derived from the oesophageal pressure tracing. The slope of the line A-C indicates the compliance line. The area of loop A, B, C, D, A indicates work due to airway resistance between the alveoli and the mouth. The inspiratory work of the lung compliance is the area of the triangle $A, C, F, A$ and the total lung work on inspiration is represented by A, B, C, F, A. In normal spontaneous breathing, expiration is not entirely passive (this would produce an exponential rather than a sine-wave expiratory pattern). The work done on expiration is indicated by the area $A, F, C, D, A .^{5}$ Thus, the total lung work per breath is the area of the rectangle $\mathrm{A}, \mathrm{E}, \mathrm{C}, \mathrm{F}, \mathrm{A}$ and is equal to twice the compliance work. The total chest work is approximately double the total lung work and so this has been inferred by doubling the latter. The episodic deviations of the loop are due to cardiac action. This distortion means that work can only be derived from these loops as an approximation over several breaths. With the Venturi "OFF," the average tidal volume was $471.4 \mathrm{ml}$ and minute ventilation was 6.61 ( $\mathrm{f}=14 / \mathrm{min}$ ). When turned "on," the figures were reduced to $396.9 \mathrm{ml}$ and $5.16 \mathrm{l}$ respectively ( $\mathrm{f}=13 / \mathrm{min}$ ). The Venturi 


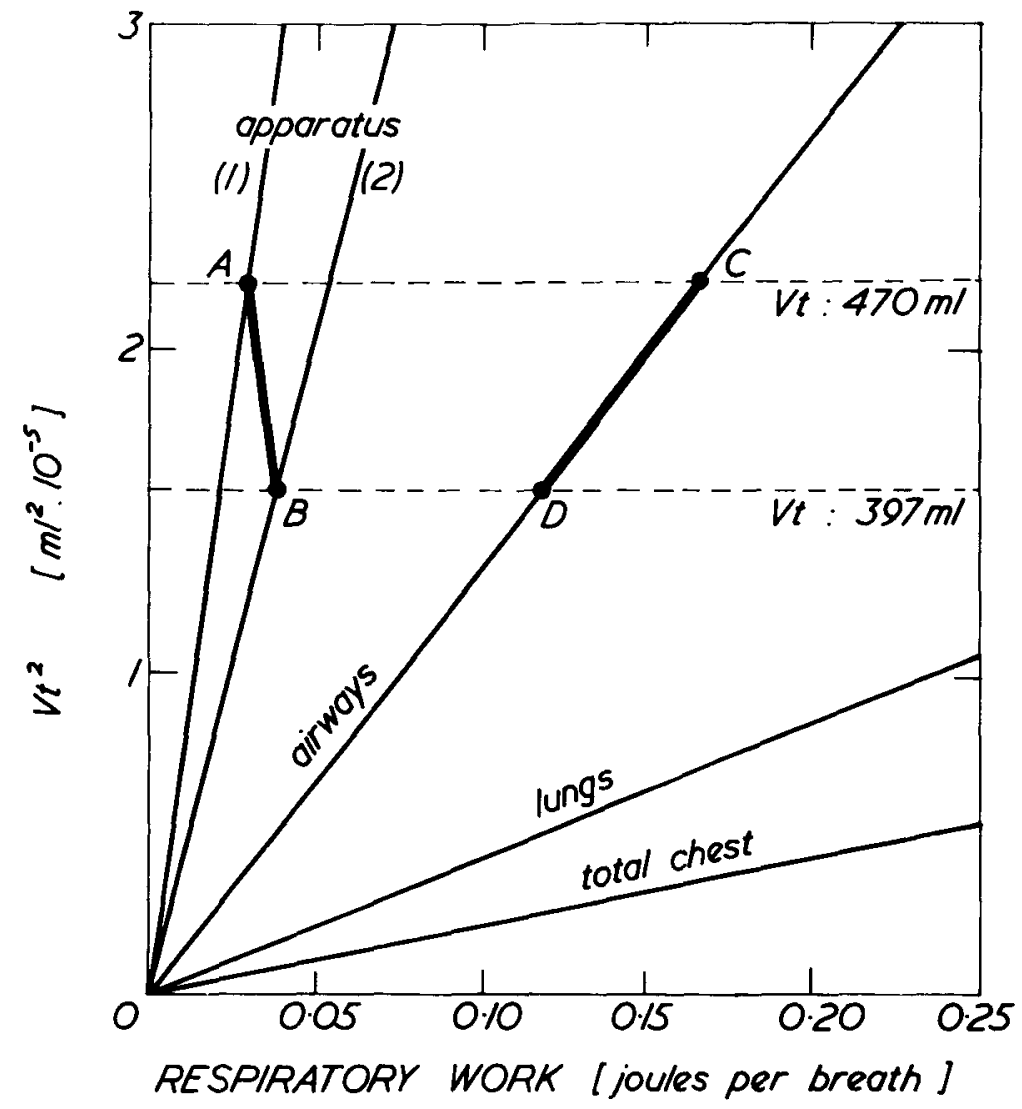

FIgUnE 13. The effect of changing ventilation on the work of breathing.

thus produced a fall in ventilation representing a 12 per cent reduction in tidal volume and a 17 per cent reduction in minute ventilation. It is clear that an undepressed individual will reduce his ventilation in response to the reduced deadspace and that this will probably reduce the total work of breathing.

The work per breath which may be attributed to the patient's airways has been correlated with tidal volume in Figure 12. The dots indicate both calibration runs and episodes of normal breathing with the various apparatus configurations. All the points fall along a straight line when ventilation is expressed as $\mathrm{Vt}^{2}$ indicating that work is proportional to the square of tidal volume. The correlation is to be expected since work is the product of volume and pressure; whilst the frequency remains the same then the pressure will be directly proportional to volume for a given waveform. The graph also indicates the average tidal ventilation of the volunteers, both while the Venturi has been operating and with it turned off. There is a reduction of airway work per breath resulting from reduced ventilation.

In Figure 13, similarly derived regression lines for apparatus work versus tidal volume has been plotted together with, for comparison, the work done on the airways, lungs, and the total chest. The two horizontal lines again indicate average 
TABLE I

Summary of the Work of Breathing in a Circle Anaesthetic System Using the NefF Circulator

\begin{tabular}{|c|c|c|}
\hline & Circulator 'On' & Circulator 'Off' \\
\hline Tidal volume frequency & $\begin{array}{l}397 \mathrm{ml} \\
13 / \mathrm{min}\end{array}$ & $\begin{array}{l}470 \mathrm{ml} \\
14 / \mathrm{min}\end{array}$ \\
\hline Work per breath on airways & 0.114 Joules & 0.170 Joules \\
\hline Total lung work/breath & 0.344 & 0.507 \\
\hline Total chest work/breath & $0.688^{*} \quad$, & 1.02 \\
\hline Apparatus work/breath & 0.042 & 0.028 \\
\hline $\begin{array}{l}\text { Total chest work with } \\
\text { apparatus/breath }\end{array}$ & 0.730 & 1.048 \\
\hline
\end{tabular}

*Total work of breathing before applying apparatus.

'Apparatus' implies use of a mask with the circle absorption system.

tidal volumes with the Venturi "OFF" and with it "on." Though the apparatus work is increased by switching on the circulator, its effect upon ventilation reduces the magnitude of the change. The relatively large reduction in airway work more than compensates for this (the heavy solid lines $A B$, and $C D$ indicate the path taken by the work calculation as a result of switching the Venturi on).

Table I summarizes the effect upon the total work of breathing of using the Neff Circulator with a circle system. These figures indicate that when an individual breathing air commences to breathe through a mask with a conventional circle system, he increases his total work of breathing by approximately 64 per cent due to increase in dead-space and apparatus resistance. If the system is equipped with a Neff Circulator and dead-space eliminating mask, the increase is only of the order of 6 per cent.

\section{The Effect of the Apparatus on Anaesthetized Patients}

Five patients, premedicated with 10 milligrammes of morphine and 0.6 milligrammes of atropine per 70 kilogrammes were anaesthetized with 250 milligrammes of thiopentone per 70 kilogrammes and anaesthesia was maintained with halothane, 0.5 per cent to 0.75 per cent in 50 per cent nitrous oxide in oxygen. Under these circumstances, ventilation was universally depressed, tidal volume being lowered to approximately $250 \mathrm{ml}$ and minute volume to 2.5 to 3.5 litres per minute. These patients made no consistent response to the use of the Venturi. Thus, there would appear to be no advantage to these patients in terms of work of breathing. However, one would expect a reduction in $\mathrm{PaCO}_{2}$ with reduced deadspace in this situation.

Two patients who were not premedicated but were induced with 500 milligrammes per $70 \mathrm{Kg}$ of propanidid (a rapidly metabolized non-barbiturate induction agent) and maintained with halothane and nitrous oxide as above did respond to the introduction of the circulator by reducing their ventilation.

From this it would appear that the full advantages of the circulator can only be expected in unpremedicated, non-depressed, lightly anaesthetized patients. 


\section{Conclusion}

The Neff Circulator is capable of completely eliminating under-mask dead-space but only when a "Double Entry" mask or similarly efficient mask design is used. There would be little or nothing to be gained from using the device with a tracheal tube in place.

The suggestion that the Neff Circulator reduced the work of breathing due to apparatus resistance is not substantiated. Indeed, the reverse would appear to be the case. However, the reduction in chest work in patients, arising from the elimination of apparatus dead-space, does reduce the total work of breathing, but only in patients who are not suffering from respiratory depression such as is common in conventional anaesthetic techniques. The advantage to this latter group of depressed patients would appear to be a fall in arterial $\mathrm{P}_{\mathrm{CO}_{2}}$ though no confirmatory measurements of this have been made.

The circulator shares an inconvenience associated with the Revell Circulator in that it causes a rise in the mean under-mask pressure which exaggerates the effects of leaks. It has been suggested that the circulator enables one circle absorption system to be used effectively with any size of patient. Provided that a suitable mask system allowing elimination of dead space is used, such an arrangement offers a lower breathing resistance than that encountered with specially designed paediatric circle absorber systems.

\section{SUMMARY}

The Neff Circulator, a device for circulating gases in an anaesthetic circle system, has been investigated in the laboratory, in conscious volunteers and in spontaneously breathing anaesthetized patients. In conjunction with a suitably designed face mask, the device is capable of eliminating apparatus dead-space. In conscious volunteers, who were capable of responding to this by reducing their tidal volumes, there was a marked reduction in the total work of breathing. However, spontaneously breathing anaesthetized patients did not respond by an alteration in the ventilation volume; it is therefore presumed that they experienced a reduction in arterial $\mathrm{P}_{\mathrm{CO}_{2}}$ as a result of the incorporation of the device.

\section{RÉSUMÉ}

Nous avons fait une étude, aussi bien en laboratoire chez des volontaires conscients que chez des malades sous anesthésie, du circulateur Neff, un appareil qui fait circuler les gaz anesthésiques dans le système de circuit par l'entremise d'un injecteur qui fonctionne par l'arrivée de gaz anesthésiques frais. L'appareil incorpore une valve d'échappement de pression modifiée qui limite la pression à l'intérieur de la machine à anesthésie à environ $60 \mathrm{~mm}$ de mercure. Le circulateur augmente légèrement la résistance de l'appareil à la ventilation, mais cet effet est contrebalancé par la réduction de l'espace mort de l'appareil qu'il est possible de réaliser. En employant un masque convenablement approprié, l'espace mort de l'appareil peut être éliminé. 
Chez les volontaires conscients en ventilation spontanée, le circuit conventionnel du système anesthésique plus le masque, augmentent le travail de la respiration de 64 pour cent à cause de la résistance de l'appareil et de l'augmentation de l'espace mort. Lorsque le système est muni d'un circulateur Neff et un masque convenable, l'augmentation n'était que de l'ordre de 6 pour cent. D'autre part, les malades sous anesthésie en respiration spontanée, de façon générale, n’ont pas répondu à la diminution de l'espace mort par une réduction du volume courant. On présume que ces malades ont subi une réduction de leur $\mathrm{PCO}_{2}$ artérielle.

\section{ACKNOWLEDGMENTS}

We are indebted to members of the Department of Anaesthetics, Cardiff, for their help and criticism during the production of this paper. In particular, we wish to thank Dr. W.W. Mapleson, Ph.D., F.Inst.P., who generously assisted us with the mathematical analysis of the work of breathing. Finally, we are deeply indebted to Professor W.W. Mushin without whose help and encouragement this paper would never have been written.

\section{REFERENCES}

1. Revelt, D.G. A circulator to eliminate mechanical dead space in circle absorption systems. Canad. Anaesth. Soc. J. 6: 98 (1959).

2. Roffey, P.J., Revell, D.G., \& Morris, L.E. An assessment of the Revell Circulator. Anaesthesiology 22: 583 (1961).

3. NefF, W.B., Burke, S.F., \& Thompson, R. A Venturi Circulator for anaesthetic systems. Anaesthesiology 29: 838 (1968).

4. Noble, W.H. Accuracy of halothane vaporizers in clinical use. Canad. Anaesth. Soc. J. 17: $135(1970)$.

5. Otis, A.B. The Work of Breathing. Amer. Physiol. Soc. Handbk. Physiol. Section III, Vol, I, Chapter 17, p. 463. Williams \& Wilkins, Baltimore. 